\title{
1 Pheromone binding protein shapes olfactory temporal 2 resolution
}

4 Yusuke Shiota ${ }^{1}$, Takeshi Sakurai ${ }^{1,2 *}$, Noriyasu Ando ${ }^{1}$, Stephan Shuichi Haupt ${ }^{1}$,

$5 \quad$ Hidefumi Mitsuno ${ }^{1}$, Takaaki Daimon ${ }^{3}$, Ryohei Kanzaki ${ }^{1}$

$7 \quad{ }^{1}$ Research Center for Advanced Science and Technology, The University of Tokyo, 4-6-

81 Komaba, Meguro-ku, Tokyo 153-8904, Japan

$9{ }^{2}$ Department of Agricultural Innovation for Sustainability, Faculty of Agriculture,

10 Tokyo University of Agriculture, 1737 Funako, Kanagawa, Atsugi 243-0034, Japan

$11{ }^{3}$ Department of Applied Biosciences, Graduate School of Agriculture, Kyoto University,

12 Kitashirakawa Oiwakecho, Sakyo-ku, Kyoto 606-8502, Japan

$14 *$ Corresponding author

15 Takeshi Sakurai, Ph.D.

16 Department of Agricultural Innovation for Sustainability, Faculty of Agriculture, Tokyo

17 University of Agriculture, 1737 Funako, Kanagawa, Atsugi 243-0034, Japan

18 Phone: $+81-46-270-6563$,

19 E-mail: ts206448@nodai.ac.jp 
22 Abstract

23 Male moths are capable of orienting towards conspecific females using sex

24 pheromones. Since pheromones are distributed as discontinuous plumes owing to

25 air turbulence, tracking intermittent stimuli with high temporal resolution is

26 suggested to be important for efficient localisation. Here, using a pheromone

27 binding protein (BmPBP1) knockout silkmoth, we revealed that the loss of

28 functional pheromone binding protein altered antennal response kinetics resulting

29 in reduced temporal resolution to intermittent pheromone stimuli on the antennae.

30 Behavioural analysis revealed that BmPBP1-knockout males exhibited

31 significantly less straight walking, which occurs when detecting pheromone stimuli,

32 especially to high frequency stimuli. Accordingly, BmPBP1-knockout males took a

33 significantly longer time to locate pheromone sources and females than did wild-

34 type males. Together, BmPBP1 plays a critical role in determining temporal

35 antennal response kinetics and that an appropriate range of temporal sensory and

36 behavioural resolutions is essential for tracking pheromone plumes for efficient

37 pheromone source localisation in the silkmoth. 


\section{Introduction}

Many animals rely on olfaction to locate potential mating partners or food sources for survival in a natural environment. Odour source localisation is a difficult task for animals because odours are distributed discontinuously owing to turbulent air flow in the natural environment; the stochastic nature of odour distribution further increases the unpredictability of odour arrival ${ }^{1-3}$. Mechanisms underlying how animals can accurately locate odour sources in such a complex environment have long been a core topic of study in the field of olfactory research.

The sex pheromone communication system in moths is one of the best examples of sophisticated odour source localisation in animals, whereby male moths detect and orient toward conspecific females using intermittent sex pheromone information emitted by females. Owing to the simple relationship between sex pheromone chemicals and the localisation behaviour, pheromone source localisation behaviours can be relatively easily induced in the laboratory. As such, this behaviour has been studied as an essential model system to better understand the general mechanisms underlying odour source localisation in animals.

Odour source localisation behaviours of male moths consist of two basic behavioural components: an upwind surge and crosswind casting ${ }^{4}$. The surge is a straight upwind flight triggered shortly after exposure to the pheromone filament, whereas crosswind casting is a self-steering counterturning that occurs when a male moth loses contact with the pheromone filaments in the plume. In the silkmoth Bombyx mori, when exposed to the pheromone, male moths exhibit straight walking at a small turning angle as a reflex behaviour (surge), followed by left and right zigzag turns (casting), with a gradually increasing turn angle when they encounter an air pocket of a pheromone plume ${ }^{5-7}$. This behavioural sequence is reset in response to every new exposure to a pheromone stimulus. Thus, search-related walking paths are highly dependent on the temporal structure of the pheromone stimuli ${ }^{5,8,9}$. When the stimulation 
66 frequency is low, males walk in complex zigzag paths, whereas a higher frequency

67 results in successive surge behaviours and straighter paths. Therefore, male antennae

68 should possess a sufficient temporal resolution to track intermittent pheromone

69 stimulation. The surge-casting (phasic-tonic) behavioural model for odour source

70 localisation is thought to be a common strategy among moth species underlying their

71 localisation behaviour ${ }^{4,10}$.

72 The importance of intermittent odour information has also been highlighted in 73 experiments using homogeneous pheromone stimulation that rarely contains fluctuating 74 pheromone filaments in the plume (referred to as a homogeneous pheromone cloud). In 75 homogeneous pheromone clouds, moths cannot sustain an upwind surge and exhibit a casting flight, leading to the inability to localise the pheromone source ${ }^{11,12}$. Later, to investigate the physiological responses to intermittent stimuli, the characteristics of sensory output to various odour frequencies, including a homogeneous pheromone cloud, were examined in the moths Grapholita molesta and Heliothis virescens ${ }^{10,13}$. In

80 response to intermittent stimuli, the electroantennogram (EAG) responses, which

81 monitor the total activity of all olfactory receptor neurons (ORNs) in the antenna, of moths reflected intermittent exposure to pheromone filaments in the plume. However, in

83 a homogeneous pheromone cloud, the responses did not show dynamic changes. These reports conclude that moths naturally receive intermittent pheromone information on

85 their antennae, and this modulates surge-casting localisation behaviour. Therefore, 86 resolving the temporal properties of odour information continuously is thought to be a 87 very important aspect of odour source localisation ${ }^{14,15}$. However, the temporal sensory 88 and behavioural resolution required for successful odour source localisation and the underlying neural and molecular mechanisms remain to be elucidated.

90 Pheromone binding proteins (PBPs) are small soluble proteins highly enriched in 91 the sensillum lymph space ${ }^{16}$. These proteins are reported to contribute to the sensitivity 92 and/or selectivity of antennal responses ${ }^{17-21}$. Also, PBPs are thought to be involved in 
93 the early inactivation of pheromones, following pheromone detection; thus, PBPs are a

94 candidate molecular factor for controlling temporal antennal responses ${ }^{22-25}$. However,

95 this hypothesis has not been experimentally tested yet. In the silkmoth B. mori, one of

96 three PBP genes named $B m P B P 1$, which is expressed in accessory cells surrounding

97 ORNs and secreted into the sensillum lymph of pheromone sensitive sensilla, is 98 reported to play an important role in pheromone detection ${ }^{26-28}$. In a previous study, we 99 established a BmPBP1-knockout silkmoth line and showed that the loss of BmPBP1

100 affected the sensitivity of antennal responses to pheromone components ${ }^{21}$. In this study, 101 using the BmPBP1-knockout silkmoth, we revealed that the temporal antennal 102 resolution of $B m P B P 1-k n o c k o u t$ male antennae to intermittent pulse trains was

103 significantly reduced. In addition, BmPBP1-knockout male moths took significantly 104 longer to locate pheromone sources owing to lowered temporal behavioural resolution, 105 resulting in inefficient source localisation. Based on our results, we will discuss the 106 effects of BmPBP1 loss and the sensory characteristics that govern the efficiency of 107 odour source localisation behaviour.

Time constant of antennal responses was altered in BmPBP1-knockout male

111 moths. In a previous study, we reported that antennal responses of BmPBP1-knockout

112 silkmoths to pheromone components were significantly lower than those of wild-type 113 moths, but antennae retained a clear responsiveness to pheromone components 114 (bombykol and bombykal) ${ }^{21}$. Using BmPBP1-knockout males, we first tested whether 115 PBPs were also involved in the temporal properties of antennal responses by 116 investigating the response and recovery time constants of EAG responses of BmPBP1117 knockout male moth antennae to single pulse stimulation with sex pheromone 118 components (Fig. 1a). Comparison of these parameters with the same bombykol dosage 119 (1000 and $10000 \mathrm{ng}$ ) revealed that there were significant differences in the kinetic 
parameters consisting of latency and recovery time constant at $10000 \mathrm{ng}$ between

121 BmPBP1-knockouts and wild-types (Fig. 1b top, 1c). Because the peak EAG amplitudes

122 of BmPBP1-knockout male antennae were significantly lower than those of wild-type

123 antennae (Fig. 1b top) $)^{21}$, we hypothesised that differences in peak amplitudes could

124 affect the temporal parameters of EAG responses. When we normalised the temporal

125 parameters using peak amplitudes, we found that recovery time constants showed a

126 positive correlation with peak amplitudes, and, as a result, normalised recovery time

127 constants of BmPBP1-knockout male antennae were significantly longer than those of

128 wild-type male antennae ( $\mathrm{p}=0.0014$ for bombykal; $\mathrm{p}=0.0017$ for bombykol) (Fig. $1 \mathrm{~b}$

129 bottom, 1d). However, the other two parameters did not show any correlation with peak

130 amplitude, and no significant differences were found in the response time constant or

131 latency of antennal responses of BmPBP1-knockout and wild-type males (Fig. 1b

132 bottom, 1d). These differences were observed with both bombykol and bombykal (Fig.

133 1d), suggesting that the loss of BmPBP1 delayed the recovery time constant of EAG

134 responses with both bombykol and bombykal.

135

\section{Kinetics of temporal antennal responses to pheromone pulse trains in}

BmPBP1-knockout moths. Because tracking intermittent pheromone pulse trains is important to locate pheromone sources in male moths, we next assessed the effects of loss of BmPBP1 on temporal antennal responses to pheromone pulse trains. Particularly, we focused on responses to bombykol because only bombykol triggers the pheromone source localisation behaviour of male silkmoths. We tested three different frequencies of pulse trains, consisting of $0.17 \mathrm{~Hz}$ as the low stimulus frequency, $0.83 \mathrm{~Hz}$ as the representative of the emission rate of pheromone from females ${ }^{29}$ and $2 \mathrm{~Hz}$ as the frequency that can induce a consecutive surge in male silkmoths ${ }^{5}$ (Fig. 2a). Consistent with single pulse experiments, the recovery time constant of EAG responses became longer in BmPBP1-knockout than in wild-type male antennae (Fig. 2a). The time 
147 required to return to baseline levels after the first bombykol stimulation (termination 148 time) was significantly longer in BmPBP1-knockout than in wild-type male moths with 149 all tested frequencies (Fig. 2b, 2c). More importantly, the termination times got longer 150 as the frequency increased and EAG responses of BmPBP1-knockout never returned to 151 baseline levels during high frequency stimuli in several tested antennae ( 1 out of 6 152 tested antennae at $0.83 \mathrm{~Hz}, 4$ out of 12 tested antennae at $2 \mathrm{~Hz}$ ). However, all EAG 153 responses of wild-type male antennae quickly recovered to baseline levels ( $\mathrm{n}=7$ at 0.83 $154 \mathrm{~Hz}, \mathrm{n}=6$ at $2 \mathrm{~Hz}$ ) (Fig. 2c).

155 To evaluate response recovery after intermittent stimuli, we calculated the valley 156 amplitudes, which were defined as the EAG amplitude where each local minimum 157 amplitude was subtracted from the baseline level amplitude (Fig. 2b, 2d, see also 158 Methods section). The valley amplitudes of BmPBP1-knockout males were significantly 159 larger than those of wild-type males when stimuli were delivered at 0.83 and $2 \mathrm{~Hz}$. In 160 comparison, the valley amplitudes of both BmPBP1-knockout and wild-type males 161 returned to baseline levels after each stimulus was delivered at $0.17 \mathrm{~Hz}$, and there was 162 no significant difference between the groups (Fig. 2d). These results indicate that 163 delayed recovery time constant in BmPBP1-knockout male antennae affects the overall 164 temporal response kinetics of EAG responses to intermittent pheromone stimuli.

lower compared to that in wild-type male moths. To understand the physiological basis of the observed temporal characteristics in EAG experiments, we next performed 169 single sensillum recordings (SSRs) of pheromone sensitive sensilla trichodea (Fig. 3a).

170 We revealed that spontaneous spike activity was not significantly different between BmPBP1-knockout and wild-type antennae, suggesting that BmPBP1 does not affect

172 spontaneous spike levels (Fig. 3b, 3c). To compare temporal kinetics, we used $10000 \mathrm{ng}$ 173 bombykol as stimuli for BmPBP1-knockout male antennae and $1000 \mathrm{ng}$ bombykol as 
174 stimuli for wild-type male antennae, which evoked similar spike counts in BmPBP1-

175 knockout male antennae and wild-type male antennae (Fig. 3b, 3c). The spike responses

176 of $B m P B P 1$-knockout male antennae at $0.17 \mathrm{~Hz}$ took significantly longer to return to

177 spontaneous spike levels, while those of wild-type antennae quickly terminated after the

178 stimulus (Fig. 3d). When antennae were stimulated at $2 \mathrm{~Hz}$, this tendency became

179 clearer, and the spike responses of all tested ORNs in BmPBP1-knockout antennae did

180 not return to spontaneous spike levels between subsequent stimuli, while wild-type

181 ORN spike responses quickly returned to spontaneous levels (Fig. 3e, 3f). These results

182 demonstrate that the loss of BmPBP1 delayed response termination of ORNs resulting

183 in a lower antennal temporal resolution in BmPBP1-knockout males.

lower compared to that of wild-type male moths. To investigate the effects of delayed termination kinetics on pheromone source localisation behaviours (Fig. 4a), we first analysed pheromone source localisation behaviours to bombykol using tethered male moths. Upon exposure to a single pulse of bombykol, each BmPBP1-knockout male moth exhibited full pheromone-induced localisation behaviour, consisting of a surge behaviour followed by zigzag turns (Fig. S1, Fig. 4b), indicating that the loss of BmPBP1 did not abolish innate behavioural sequences, despite the surge duration of BmPBP1-knockout male moths being significantly longer than that of wild-type male moths (Fig. 4b).

If $B m P B P 1-k n o c k o u t$ males perceived intermittent stimuli as continuous signals owing to delayed response kinetics, we hypothesised that behavioural patterns to pulse trains should be changed, especially in terms of resetting behaviour sequences. In response to $0.17 \mathrm{~Hz}$ intermittent bombykol stimulation, to which $B m P B P 1$-knockout antennae return to baseline levels, both $B m P B P 1$-knockout and wild-type male moths 
201 pulse induced the resetting of behaviour sequences. However, following $0.83 \mathrm{~Hz}$ and 2

$202 \mathrm{~Hz}$ bombykol pheromone pulse trains, BmPBP1-knockout male moths displayed lower

203 surge rates - the ratio of surge duration against total locomotion duration (see

204 Methods) - and higher zigzag turn rates than wild-type male moths (Fig. 4c, d). Further,

205 BmPBP1-knockout male moths exhibited fewer longer surges (defined as a surge lasting

206 more than 2 seconds) than wild-type male moths (Fig. 4e), indicating that BmPBP1-

207 knockout males failed to exhibit successive surge behaviours in response to intermittent

208 pheromone stimuli at $2 \mathrm{~Hz}$. Importantly, differences in surge rates were well correlated

209 with EAG and SSR results; males restarted surge behaviours to each pheromone

210 stimulus under stimulus conditions that allowed antennal responses to return to baseline

211 levels, presumably owing to failure to clearly detect the onset of the subsequent

212 stimulus. Thus, our results indicate that lower temporal antennal resolution reduces

213 temporal behavioural resolution in BmPBP1-knockout males. pheromone source localisation in BmPBP1-knockout male moths.

217 To assess whether changes in the behavioural patterns of BmPBP1-knockout 218 males affect odour source localisation, we investigated pheromone source localisation 219 behaviours to $2 \mathrm{~Hz}$ pheromone pulse trains in a wind tunnel under free walking 220 conditions. We analysed two criteria for efficient pheromone source localisation: 221 success rate and localisation time. To compensate for differences in EAG sensitivity 222 (Fig. 1) and to test the effects of pheromone dose on pheromone source localisation, the 223 behaviours of BmPBP1-knockout and wild-type males were tested with 100-10000 ng 224 and 1-100 ng bombykol, respectively. Both BmPBP1-knockout and wild-type males 225 could localise the pheromone source for all tested doses of bombykol with a similar 226 success rate (Fig. 5a). However, BmPBP1-knockout males took significantly longer to 227 localise the pheromone source than wild-type males (Fig. 5b). Therefore, though 
BmPBP1-knockout males still possess the ability to localise the pheromone sources, the efficiency of their localisation behaviour in terms of localisation time was significantly reduced in BmPBP1-knockout males.

The walking traces of BmPBP1-knockout males had distinct patterns with more turning and less successive surge behaviour compared with wild-type males (Fig 5c). Indeed, a detailed analysis of the traces revealed that BmPBP1-knockout males exhibited significantly shorter surge distances and a larger summed turning angle during localisation than wild-type males (Fig. 5d, e). Exposure to relatively high bombykol concentrations in BmPBP1-knockout male moths (KO: 1000-10000 ng) and low bombykol concentrations in wild-type male moths (WT: 1-10 ng) did not alter the characteristics of localisation behaviours (Fig. 5a-e). Lastly, we examined localisation behaviour to female silkmoths and found that behavioural parameters including success rate (Fig. 5f), localization time (Fig. 5g), surge distance (Fig. 5h) and all turn angles (Fig. 5i) showed the same characteristics with those observed to bombykol. Taken together, these results indicate that behavioural deficits caused by the low temporal antennal resolutions of male moths are responsible for the inefficiency of odour source localisation in BmPBP1-knockout males.

\section{Discussion}

In this study, we demonstrated that the temporal sensory characteristics of antennae are crucial for efficient pheromone source localisation and that BmPBP1 is involved in shaping the temporal sensory characteristics of antennae to pheromone stimulation in B. mori. Since the discovery of PBPs in 1981 in Antheraea polyphemus ${ }^{16}$, PBPs have been suggested to play important roles in various aspects of pheromone detection in moths. Although previous studies have provided evidence that PBPs can enhance the sensitivity of antennal response to pheromones ${ }^{20,21}$, no study has provided in vivo experimental evidence for the contribution of PBPs for improving temporal 
sensory resolution, one of the most important aspects in odour source localisation under

256 natural conditions. Our physiological and behavioural analyses using BmPBP1-

257 knockout silkmoths present the first evidence supporting the functional role of BmPBP1

258 in determining the temporal kinetics of pheromone responses.

Odour source localisation utilises the natural intermittency of odour stimulation to promote a surge when a stimulus pulse is encountered. This behavioural strategy for odour source localisation is, at present, widely accepted in moth species, based on the correspondence between physiological antennal responses and surge behaviours during

263 localisation ${ }^{10,13}$. Therefore, moths require mechanisms that allow for the faithful 264 representation of intermittent odour information at the level of the antennal receptors, as well as a strategy to reflect sensory information in behaviours with sufficient temporal resolution. In this study, we showed that BmPBP1-knockout males had a reduced temporal antennal resolution compared with wild-type, resulting in the inefficient localisation to odour sources. Even for the localisation to female silkmoths, similar behavioural deficits, such as a shorter surge distance, longer turning behaviour and longer localisation time, were observed in $B m P B P 1$-knockout males. Therefore, these results indicate that moths possess an appropriate range of temporal antennal and behavioural resolutions to efficiently localise odour sources in a dynamically changing environment. Though sensitivity of BmPBP1-knockout antennae is lower than that of wild-type antennae, the behavioural deficits are thought to be caused by the alternation of temporal kinetics, but not by the lowered sensitivity, as the behavioural deficits were observed in response to pheromone stimuli that induced similar EAG peak amplitudes in both BmPBP1-knockout and wild-type antennae.

Our EAG results demonstrated that the recovery time of EAG responses of BmPBP1-knockout male antennae was significantly longer than those of wild-type male antennae, which resulted in the lower temporal resolution of EAG responses to pulsed 
282 ORNs in the antenna, the actual relationship between EAG responses and the spike 283 activity of individual ORNs is not clear. Thus, it is important to note that consistent 284 temporal characteristics were also observed at the level of single ORN spike responses, 285 showing that EAG response kinetics in BmPBP1-knockout antennae reflects changes in 286 temporal spike characteristic of ORNs.

287 Similar temporal alterations in antennal and behavioural responses to odour pulse 288 trains have been previously reported in the oriental fruit moth Grapholita molesta ${ }^{30,31}$. 289 Under cool temperature conditions, antennal responses of G. molesta males to 290 pheromones were reduced, and they were unable to keep up with high frequency pulsed 291 pheromone stimuli due to the inability to generate well-contrasted on-off spike 292 representations to each stimulus. This characteristic property of the spike response of 293 ORNs is called "attenuation",30. Under similar cooling conditions, male moths failed to 294 initiate successive surge behaviours and could not locate an odour source ${ }^{31}$. Although 295 the underlying mechanism that affects the antennal response characteristics and 296 behaviours may be different, these studies also indicate the importance of the temporal 297 characteristics of antennal responses for efficient pheromone source localisation. In our study, we revealed that $\mathrm{BmPBP} 1$ is one factor related to temporal antennal resolution and that temporal sensory representations corresponding to odour dynamics play a key role in the quick behavioural reset strategy for efficient localisation.

301 We found that the stimuli frequencies to which EAG responses could recover 302 from peak amplitude to baseline levels corresponded to those where behavioural 303 sequences of male moths were reset. Therefore, after peak neuronal activity, returning 304 to spontaneous baseline activity can be important for tracking odour filaments by 305 continuously resetting behavioural sequences, rather than only peak amplitude detection. 306 Previous studies have reported the temporal antennal resolution of several moth species 307 based on the peak frequency analyses of EAG recordings ${ }^{32,33}$. According to these 308 reports, antennae of male B. mori have a potential temporal resolution to intermittent 
309 odour pulses of up to $25 \mathrm{~Hz}$. However, since EAG responses to high frequency

310 pheromone stimulation in those reports do not recover to baseline levels after peak

311 response, there is a possibility that not every odour stimulus is resolved to induce

312 resetting behavioural sequences and initiation of surge behaviour. Thus, the potential

313 temporal resolution of antennae may differ from the antennal temporal resolution for a

314 behavioural reset. In other words, sensory responses may turn into 'fused' information

315 for male moth behaviour when tracking an odour plume at a frequency where neural

316 activity does not return to spontaneous baseline activity before a response to a

317 subsequent odour stimulus. In the future, investigation of the behavioural patterns of

318 wild-type animals to high frequency stimuli that induce antennal responses without

319 returning to baseline levels can shed light on antennal response parameters crucial for

320 the reset of behaviour sequences.

321 Previous kinetics model analyses proposed that rapid inactivation of pheromone

322 molecules after they activate pheromone receptors plays a critical role in controlling the

323 kinetics of pheromone responses and that PBPs were one candidate molecular

324 component of pheromone inactivation ${ }^{23-25}$. Our results showing that the loss of

325 BmPBP1 delayed recovery time constants strongly support the idea that BmPBP1 is

326 involved in the rapid inactivation of pheromone molecules. PBPs have shown to be

327 involved in sensitive detection of pheromones by efficiently solubilising pheromone

328 molecules into the sensillum lymph and protecting them from enzymatic degradation

329 during transportation to the vicinity dendritic membrane of ORNs, where pheromone

330 receptors resides ${ }^{21,22}$. Therefore, PBPs play multiple functional roles both before and

331 after pheromone detection by pheromone receptors. Further electrophysiological,

332 biochemical and molecular analyses of BmPBP1-knockout moths will help reveal the

333 detailed mode of action underlying how PBPs can perform these different functions in

334 the process of pheromone detection.

335 In this study, we reported that BmPBP1 contributes to the temporal control of 
antennal responses, and its absence lowered the antennal temporal resolution, critically affecting efficient odour source localisation. Our results could provide a new methodology for controlling pest insects by modulating odour source localisation behaviour. Furthermore, strategies to represent spatio-temporal airborne odours in the sensory system by quickly terminating signals after detection, and to reset sequential behavioural patterns in response to sensory input, are thought to be equally effective for the development of artificial odour source searching algorithms.

\section{Methods}

Animals and chemicals. We used BmPBP1-knockout moths, which were generated using transcription activator-like effector nuclease (TALEN)-mediated gene targeting, as described in a previous study ${ }^{21}$. Larvae were reared on an artificial diet (Nihon Nosan Kogyo, Yokohama, Japan) at $25^{\circ} \mathrm{C}$ under a $16: 8 \mathrm{~h}$ (light/dark) photoperiod. Following eclosion, one to seven day old male moths were used for the experiments. Subsequent to all experiments in this study, the genotype of all BmPBP1knockout males was determined by PCR, as previously described ${ }^{21}$. The purity $(>99.5 \%)$ of synthetic bombykol and bombykal was verified by gas chromatography using previously described conditions ${ }^{34,35}$, and they were kindly provided by Dr. S. Matsuyama from the University of Tsukuba, Japan.

Electroantennogram (EAG) recordings. An antenna of a male moth was excised at the base, and a few antennomeres at the tip were cut off. The antenna was then mounted on the EAG probe using electrode gel (SPECTRA 360; Parker Laboratories, Fairfield, NJ, USA). A glass cartridge (inner diameter, $5 \mathrm{~mm}$ ) was prepared for stimulation by inserting a piece of filter paper $(1.5 \times 1.5 \mathrm{~cm})$, and $5 \mu \mathrm{L}$ of a pheromone solution in $n$-hexane was administered. A charcoal-purified airstream (1 $\mathrm{L} / \mathrm{min}$ ) was passed through the glass cartridge and directed onto the antenna. The EAG 
363

364

365

responses were amplified using a custom-made amplifier (Minegishi and Kanzaki, unpublished), band-pass filtered at 0.16 to $300 \mathrm{~Hz}$, and digitised at $1 \mathrm{kHz}$ (USB-6210; National Instruments, Austin, TX, USA). The data were analysed using a customwritten program (MATLAB; Mathworks, Natick, MA, USA). Baseline levels were calculated from $2 \mathrm{sec}$ of data recording before the stimulus. The start time of the response was defined as the time the EAG amplitude exceeded the baseline level by \pm 2.5 standard deviations. The response time constant was defined as the time of the response phase, from the start of response to $63.2 \%$ of the absolute EAG response amplitude. The recovery time constant was defined as the time of the settling phase, from the peak amplitude to $63.2 \%$ of the absolute EAG response amplitude. The valley amplitude was defined as the EAG response amplitude where each local minimum amplitude was subtracted from the baseline level. The termination time was defined as the time from the peak amplitude to the baseline level by $\pm 5 \%$ standard error of the mean (SEM). The latency was calculated from the start time by subtracting the arrival time of the pheromone on the antenna that was estimated using a method previously described $^{36}$.

Single sensillum recording (SSR). Single sensillum recordings were performed in a Faraday cage. Moths were fixed on a custom-made acrylic chamber under an Olympus BX50WI (500×) microscope. The antennae were stabilised with dental wax (GC Corporation, soft plate wax), and the basement segments were fixed with a resin bond (GC Corporation, G-Fix). Spike responses were recorded by a sharpened tungsten wire electrode (diameter $0.5 \mathrm{~mm}$, tip approximately $1 \mu \mathrm{m}$ ) inserted into the bases of pheromone sensitive long sensilla trichodea on the antennae. As a reference electrode, a silver wire was inserted into the compound eye of the moth. Pheromone was delivered by injecting pheromone pulses into a charcoal-purified and moistened continuous airstream $(1 \mathrm{~L} / \mathrm{min})$, to reduce any mechanical artefacts. Spike responses were band- 
pass filtered at 300 to $3 \mathrm{k} \mathrm{Hz}$ and amplified (Nihon Koden, MEZ-8300). All spike responses were digitised at $10 \mathrm{kHz}$. The spontaneous spike rate was calculated from 2 $\mathrm{sec}$ of data recording before the stimulus, with a time bin of $100 \mathrm{~ms}$. We analysed data with a custom MATLAB (Mathworks, MA, Natick, USA) program and Spike2 software (Cambridge Electronic Design Limited, UK).

Behavioural experiments using tethered moths. Scales on the dorsal thorax of moths were removed, and a copper wire holder was attached to the thorax with glue. Moths were placed on the top of a $70 \mathrm{~mm}$ diameter polystyrene foam ball. The ball was supported by a plastic funnel with an electrical fan attached under the ball. The air flow generated by the electric fan kept the ball floating in the air to reduce friction and enable moths to behave during locomotion. Pulsed pheromone stimulation of $200 \mathrm{~ms}$ duration at $0.83 \mathrm{~Hz}$ and $2 \mathrm{~Hz}$ frequency and stimulation of 1 second at $0.17 \mathrm{~Hz}$ frequency was used. Wild-type and BmPBP1-knockout males were stimulated with $100 \mathrm{ng}$ and 10000 ng bombykol, respectively. Based on a previous study using tethered moths, the surge behaviour was defined as straight walking with a small angle, at an accumulated angular velocity $\leq 8^{\circ}$, when the accumulated walking distance $\geq 1 \mathrm{~mm}$, with a forward velocity $\geq 1 \mathrm{~mm} / \mathrm{sec}$, using a time bin of $200 \mathrm{~ms}$. The zigzag turn behaviour was defined as turning behaviour with a large angle, at an accumulated angular velocity $\geq 8 \%$ sec, with an accumulated forward velocity $\leq 10 \mathrm{~mm} / \mathrm{sec}$. These parameters were adjusted to remove trackball noise from oscillations caused by stepping of the moth according to a previous study ${ }^{37}$. Pheromone source localisation behaviours of moths were recorded with an optical mouse attached behind the polystyrene ball. Surge rate was defined as the ratio of total surge duration to total locomotion duration containing both surge and zigzag turns. We processed data based on these criteria with a custom MATLAB (Mathworks, MA, Natick, USA) program. 
Wind tunnel experiments. We performed odour source localisation experiments 418 in a wind tunnel $(1800 \times 900 \times 300 \mathrm{~mm} \mathrm{~L} \times \mathrm{W} \times \mathrm{H})$ at $25-28^{\circ} \mathrm{C}$. Pulsed pheromone 419 stimulation of $200 \mathrm{~ms}$ duration at $2 \mathrm{~Hz}$ frequency was controlled by an electric valve, 420 and wind velocity was controlled at $0.5-0.7 \mathrm{~m} / \mathrm{s}$. For the odour source localisation 421 experiments, both $B m P B P 1$-knockout and wild-type male moths were used within 1 to 4 days after eclosion. Synthetic bombykol (1, 10, 100, 1000 and $10000 \mathrm{ng})$ and wild-type females were used for pheromone stimulation. Moths were placed $50 \mathrm{~cm}$ downstream of a pheromone source. The pheromone source localisation behaviour of male moths was captured with a digital video camera at a frame rate of $30 \mathrm{~Hz}$. Surge was defined as straight walking with a small angle, at an angular velocity $\leq 5 \% \mathrm{sec}$, with the accumulated turn angle $\leq 30 \% \mathrm{sec}$, with a forward velocity $\geq 1 \mathrm{~mm} / \mathrm{sec}$ and a walking distance $\geq 1 \mathrm{~mm}$, using a bin size of $200 \mathrm{~ms}$ based on previous studies ${ }^{38}$. Behaviours that did not correspond to these criteria were seen as stopping and switching directions and were not included in our analyses. The other behaviours (at angular velocity $\geq$ $5 \%$ sec, with accumulated turn angle $\geq 30 \%$ sec) were classified as zigzag turns. We processed image data based on these criteria with customised Java and R scripts ( $R$ Development Core Team, 2010). between wild-type and BmPBP1-knockout moths, we used Student's $t$-test, Fisher's exact probability test, the Steel-Dwass test and an ANCOVA test. Statistical significance was calculated using Microsoft Excel 2016, a commercial macroprogram

439 (Statcel version 4; Seiun-sya, Japan) and custom VBA and MATLAB (Mathworks, MA, Natick, USA) programs. The error bars shown in the figures represent the SEMs. The asterisks indicate significant differences between the groups $\left({ }^{*} p<0.05, * * p<0.01\right)$.

442 The different letters indicate significant differences according to the Steel-Dwass test 443 and Fisher's exact probability test. 


\section{References}

1. Murlis, J., \& Jones, C. Fine-scale structure of odour plumes in relation to insect orientation to distant pheromone and other attractant sources. Physiological Entomology. 6, 71-86 (1981).

2. Murlis, J., Elkinton, J. S., \& Carde, R. T. Odor plumes and how insects use them. Annu Rev Entomol. 37, 505-532 (1992).

3. Murlis, J., Willis, M. a, \& Cardé, R. T. Spatial and temporal structures of pheromone plumes in fields and forests. Physiological Entomology. 25, 211-222 (2001).

4. Baker, T.C. Upwind flight and casting flight: Complementary phasic and tonic systems used for location of sex pheromone sources by male moths in ISOT $X$, Proc. 10th Intl. Symp. Olfac. Taste. (ed. Døving.K.) 18-25 (GCS/AS Oslo, 1990).

5. Kanzaki, R., Sugi, N., \& Shibuya, T. Self-generated zigzag turning of Bombyx mori males during pheromone-mediated upwind walking. Zoological Science. 9, 515-527 (1992).

6. Haupt, S. S., Sakurai, T., Namiki, S., Kazawa, T. \& Kanzaki, R. Olfactory information processing in moths in The neurobiology of olfaction (ed. Menini, A.) 71-112 (CRC Press, 2010).

7. Sakurai, T., Namiki, S. \& Kanzaki, R. Molecular and neural mechanisms of sex pheromone reception and processing in the silkmoth Bombyx mori. Front. Physiol. 5, 125 (2014).

8. Kramer, E. Turbulent diffusion and pheromone-triggered anemotaxis in Mechanisms in Insect Olfaction (ed. Payne, T. L., Birch, M. C., and Kennedy, C. E. J.) 59-67 (Oxford University Press, 1986).

9. Kramer, E. Attractivity of pheromone surpassed by time-patterned application of two nonpheromone compounds. J Insect Behavior, 5, 83-97 (1992). 
10. Vickers, N. J., \& Baker, T. C. Reiterative responses to single strands of odor promote sustained upwind flight and odor source location by moths. Proceedings of the National Academy of Sciences of the United States of America, 91, 5756-5760 (1994).

11. Kennedy, J. S., Ludlow, A. R., \& Sanders, C. J. Guidance system used in moth sex attraction. Nature. 288, 475-77 (1980).

12. Kennedy, J. S., Ludlow, A. R., \& Sanders, C. J. Guidance of flying male moths by wind borne sex pheromone. Physiological Entomology. 6, 395-412 (1981).

13. Baker, T. C., Willis, M. A., Haynes, K. F., \& Phelan, P. L. A pulsed cloud of sex pheromone elicits upwind flight in male moths. Physiological Entomology. 10, 257-265 (1985).

14. Rumbo, E. R. \& Kaissling, K. E. Temporal resolution of odour pulses by three types of pheromone receptor cells in Antheraea polyphemus. J Comp Physiol A. 165, 281-291 (1989).

15. Marion-Poll, F. \& Tobin, T. R. Temporal coding of pheromone pulses and trains in Manduca sexta. J Comp Physiol A. 171, 505-512 (1992).

16. Vogt, R. G. \& Riddiford, L. M. Pheromone binding and inactivation by moth antennae. Nature. 293, 161-163 (1981).

17. Gräter, F., Xu, W., Leal, W. \& Grubmueller, H. Pheromone discrimination by the pheromone-binding protein of Bombyx mori. Structure. 14, 1577-1586 (2006).

18. Große-Wilde, E., Svatos, A. \& Krieger, J. A pheromone-binding protein mediates the bombykol-induced activation of a pheromone receptor in vitro. Chem. Senses 31, 547-555 (2006).

19. Hooper, A. M. et al. High-throughput ESI-MS analysis of binding between the Bombyx mori pheromone-binding protein BmorPBP1, its pheromone components and some analogues. Chem Commun. 14, 5725-27 (2009). 
20. Ye, Z. F. et al. Functional characterization of PBP1 gene in Helicoverpa armigera (Lepidoptera: Noctuidae) by using the CRISPR/Cas9 system. Sci. Rep. 7, 8470 (2017).

21. Shiota, Y. et al. In vivo functional characterisation of pheromone binding protein-1 in the silkmoth, Bombyx mori. Sci Rep 8, 13529 (2018).

22. Ziegelberger, G. Redox-shift of the pheromone-binding protein in the silkmoth Antheraea polyphemus. Eur. J. Biochem. 232, 706-711 (1995).

23. Kaissling, K. E., \& Seewiesen, M. V. Olfactory perireceptor and receptor events in moths : A Kinetic Model. Chem Senses, 26, 125-150 (2001).

24. Kaissling, K. E. Olfactory perireceptor and receptor events in moths: a kinetic model revised. J Comp Physiol A. 195, 895-922 (2009).

25. Kaissling, K. E. Kinetics of olfactory responses might largely depend on the odorant - receptor interaction and the odorant deactivation postulated for flux detectors. Journal of Comparative Physiology A. 199,879-896 (2013).

26. Sakurai, T. et al. Identification and functional characterization of a sex pheromone receptor in the silkmoth Bombyx mori. Proc. Natl. Acad. Sci. USA. 101, 16653-16658 (2004).

27. Maida, R., Mameli, B., Mueller, J., Krieger, J. \& Steinbrecht R. A. The expression pattern of four odorant-binding proteins in male and female silk moths, Bombyx mori. J. Neurocytol. 34, 149-163 (2005).

28. Forstner, M., Gohl, T., Breer, H. \& Krieger, J. Candidate pheromone binding proteins of the silkmoth Bombyx mori. Invertebrate Neurosci. 6, 177-187 (2006).

29. Fujiwara, T. et al. Odorant concentration differentiator for intermittent olfactory signals. Journal of Neuroscience. 34, 16581-16593 (2014).

30. Baker, T. C., Hansson, B. S., Löfstedt, C., \& Löfqvist, J. Adaptation of antennal neurons in moths is associated with cessation of pheromone-mediated upwind flight. Proceedings of the National Academy of Sciences of the United States of 
America. 85, 9826-9830 (1988).

31. Linn, C. E., Campbell, M. G., \& Roelofs, W. L. Temperature modulation of behavioural thresholds controlling male moth sex pheromone response specificity. Physical. Entomol. 12, 291-306 (1988).

32. Bau, J., Justus, K. a., \& Cardé, R. T. Antennal resolution of pulsed pheromone plumes in three moth species. Journal of Insect Physiology. 48, 433-442 (2002).

33. Bau, J., Justus, K. a., Loudon, C., \& Cardé, R. T. Electroantennographic resolution of pulsed pheromone plumes in two species of moths with bipectinate antennae. Chemical Senses. 30, 771-780 (2005).

34. Fujii, T. et al. Female sex pheromone of a lichen moth Eilema japonica (Arctiidae, Lithosiinae): Components and control of production. J. Insect Physiol. 56, 1986-1991 (2010).

35. Uehara, T. et al. Single-component pheromone consisting of Bombykal in a diurnal hawk moth, Neogurelca himachala sangaica. J. Chem. Ecol. 42, 517522 (2016).

36. Szyszka, P., Gerkin, R. C., Galizia, C. G., \& Smith, B. H. High-speed odor transduction and pulse tracking by insect olfactory receptor neurons. Proceedings of the National Academy of Sciences of the United States of America. 111, 16925-30 (2014).

37. Pansopha, P., Ando, N., \& Kanzaki, R. Dynamic use of optic flow during pheromone tracking by the male silkmoth, Bombyx mori. The Journal of Experimental Biology. 217, 1811-20 (2014). 


\section{Acknowledgements}

553 We thank Dr. Ryo Minegishi for the development of the EAG amplifier; Mr. Takuya 554 Nakajo and Ms. Junko Tsuchiya and Ms. Akane Kitazono-Itoigawa for technical 555 assistance in rearing silkmoths; and Dr. Shigeru Matsuyama for providing bombykol. 556 This work was supported by a Grant-in-Aid for Young scientists (A) (26712027),

557 Grant-in-Aid for Scientific Research (B), Japan Society for the Promotion of Science 558 (JSPS), Japan, awarded to T.S. and by a Grant-in-Aid for Scientific Research (B) 559 (15H04399), JSPS, Japan, awarded to R.K.

560

561 Author contributions: Y.S., T.S., and R.K. designed the research; Y.S., T.S., N.A., 562 S.S.H., and H.M. performed the research; T.D. contributed new reagents/analytic tools; 563 Y.S. and T.S. analysed the data; and Y.S. and T.S. wrote the paper.

Competing interests: The authors declare no competing interests.

Figure legends

Figure 1. Antennal response kinetics in BmPBP1-knockout male moths. (a)

569 Parameters considered in the antennal response kinetics analysis of EAG recordings. (b)

570 Representative EAG responses of BmPBP1-knockout (blue) and wild-type (red) male antennae to $10000 \mathrm{ng}$ bombykol stimulation (top), and responses to $10000 \mathrm{ng}$ bombykol stimulation in BmPBP1-knockout (blue) and $100 \mathrm{ng}$ bombykol stimulation in wild-type

573 (red) male antennae (bottom). The stimulus was applied for $200 \mathrm{~ms}$, as indicated by the 574 solid line on the trace. (c) Kinetic analysis of EAG responses in BmPBP1-knockout 575 (blue; $n=11)$ and wild-type (red; $n=5)$ male antennae. Error bars represent $\pm \mathrm{SEM}$. The 576 asterisks indicate significant differences between the groups $(* * p<0.01)$, as determined 577 using Student's t-test for comparing pairs of data. (d) Kinetic analysis of EAG 578 responses of $B m P B P 1$-knockout (blue; $n=11$ ) and wild-type (red; $n=5$ ) antennae 
579 normalised by peak EAG amplitude. Broken lines indicate linear regression curves. An

580 ANCOVA test was used to detect significant differences between wild-type and

581 BmPBP1-knockout datasets for recovery time, while significant differences between the 582 groups were not detected in the other two parameters $(* * p<0.01)$. NS indicates not 583 significant.

584

585 Figure 2. Analysis of antennal response kinetics to pulsed pheromone stimuli in 586 BmPBP1-knockout male moths. (a) Representative EAG responses to pulsed 587 pheromone trains in BmPBP1-knockout (blue) and wild-type (red) male antennae at $5880.17 \mathrm{~Hz}, 0.83 \mathrm{~Hz}$ and $2 \mathrm{~Hz}$. The stimulus was applied for $200 \mathrm{~ms}$, as indicated by the 589 solid line on the trace. The broken line indicates baseline level of each EAG trace. (b) 590 Parameters considered in the antennal response kinetics analysis of EAG recording to 591 pulsed pheromone stimuli. (c) Termination time of EAG responses to pulsed pheromone 592 trains in BmPBP1-knockout (blue) and wild-type (red) antennae at $0.17 \mathrm{~Hz}(\mathrm{KO} ; \mathrm{n}=9$, $593 \mathrm{WT} ; \mathrm{n}=9), 0.83 \mathrm{~Hz}(\mathrm{KO} ; \mathrm{n}=6, \mathrm{WT} ; \mathrm{n}=7)$ and $2 \mathrm{~Hz}(\mathrm{KO} ; \mathrm{n}=12, \mathrm{WT} ; \mathrm{n}=6)$. Error bars 594 represent \pm SEM. The asterisks indicate significant differences between the groups $(* * p$ $595<0.01$ ), as determined using Student's t-test for comparing pairs of data. (d) Valley 596 amplitude of male antennae to pheromone stimuli in BmPBP1-knockout (blue) and 597 wild-type (red) at $0.17 \mathrm{~Hz}(\mathrm{KO} ; \mathrm{n}=9$, WT; n=9), $0.83 \mathrm{~Hz}(\mathrm{KO} ; \mathrm{n}=7, \mathrm{WT} ; \mathrm{n}=7)$ and $2 \mathrm{~Hz}$ $598(\mathrm{KO} ; \mathrm{n}=16, \mathrm{WT} ; \mathrm{n}=7)$. The asterisks indicate significant differences between the groups $599 \quad(* * p<0.01)$, as determined using Student's t-test for comparing pairs of data. NS 600 indicates not significant.

601

602 Figure 3. Analysis of antennal temporal resolution to pheromone pulse trains in 603 BmPBP1-knockout male moths. (a) Representative spike responses of long sensilla 604 trichodea in BmPBP1-knockout (blue) and wild-type (red) male antennae to pheromone 605 pulse stimuli at $0.17 \mathrm{~Hz}$ and $2 \mathrm{~Hz}$. Solid lines on the trace represent the timing of 
606

607

608

609

610

611

612

613

614

615

616

617

618

619

620

621

622

623

624

625

626

627

628

629

630

631

632

intermittent bombykol stimuli. (b) Comparison of spontaneous and elicited spike numbers. Spontaneous spikes were calculated with a time bin of 2 seconds before the first stimulus was presented to $B m P B P 1$-knockout (blue; $\mathrm{n}=9$ at $0.17 \mathrm{~Hz}, \mathrm{n}=8$ at $2 \mathrm{~Hz}$ ) and wild-type (red; $\mathrm{n}=13$ at $0.17 \mathrm{~Hz}, \mathrm{n}=11$ at $2 \mathrm{~Hz}$ ) male antennae; spike numbers were calculated with a time bin of 5 seconds from the stimulus at $0.17 \mathrm{~Hz}$ and (c) with a time bin of 3.5 seconds after the stimulus at $2 \mathrm{~Hz}$. Error bars represent \pm SEM. The asterisks indicate significant differences between the groups $\left({ }^{* *} p<0.01\right)$, as determined using Student's $t$-test for comparing pairs of data. (d) Comparison of the termination time of spikes between BmPBP1-knockout and wild-type at $0.17 \mathrm{~Hz}$. Error bars represent \pm SEM. The asterisks indicate significant differences between the groups $(* * p<0.01)$, as determined using Student's t-test for comparing pairs of data. (e) Spike rate in time bins of $100 \mathrm{~ms}$ in BmPBP1-knockout (blue; $\mathrm{n}=9$ ) and wild-type (red; $\mathrm{n}=13$ ) male antennae at $0.17 \mathrm{~Hz}$ and (f) those of $100 \mathrm{~ms}$ in BmPBP1-knockout (blue; $\mathrm{n}=8$ ) and wild-type (red; $\mathrm{n}=11$ ) male antennae at $2 \mathrm{~Hz}$. Error bars represent \pm SEM. The asterisks indicate significant differences between the groups $(* p<0.05, * * p<0.01)$, as determined using Student's t-test for comparing pairs of data. NS indicates not significant.

\section{Figure 4. Behavioural responses of tethered BmPBP1-knockout moths to} intermittent pheromone pulses. (a) Schematic diagram of the pheromone-triggered programmed behaviour and pheromone source localisation strategy of a male silkmoth, B. mori. (b) Analysis of pheromone-triggered programmed behaviour in BmPBP1knockout (blue; $n=9$ ) and wild-type (red; $n=16$ ) male moths to single pulsed stimulation. Bombykol pulse stimuli were applied for 1 second. Error bars represent \pm SEM. The asterisks indicate significant differences between the groups $\left({ }^{* *} p<0.01\right)$, as determined using Student's $t$-test for comparing pairs of data. (c) Representative trace of the body angle of tethered BmPBP1-knockout (blue) and wild-type male (red) moths to pulsed bombykol stimuli at $0.17 \mathrm{~Hz}$ and $2 \mathrm{~Hz}$. (d) Surge rate in BmPBP1-knockout (blue) and 
633

634

635

636

637

638

639

640

641

642

643

644

645

646

647

648

649

650

651

652

653

654

655

656

657

658

659

wild-type (red) male moths to bombykol pulse trains at $0.17 \mathrm{~Hz}(\mathrm{KO} ; \mathrm{n}=9$, WT; $\mathrm{n}=16)$, $0.83 \mathrm{~Hz}(\mathrm{KO} ; \mathrm{n}=10, \mathrm{WT} ; \mathrm{n}=7)$ and $2 \mathrm{~Hz}(\mathrm{KO} ; \mathrm{n}=9$, WT; $=9)$. Error bars represent \pm SEM. The asterisks indicate significant differences between the groups $(* * p<0.01)$, as determined using Student's t-test for comparing pairs of data. (e) Scatter plot of each surge based on surge duration in BmPBP1-knockout (blue; $n=9$ ) and wild-type (red; $\mathrm{n}=9$ ) male moths. Circles indicate the distribution of individual data. Solid circles indicate the first surge that was induced by the first bombykol stimuli. NS indicates not significant.

\section{Figure 5. Performance of pheromone source localisation in BmPBP1-knockout}

male moths. (a) Success rate of pheromone source localisation of BmPBP1-knockout (blue) and wild-type (red) male moths at $2 \mathrm{~Hz}$ (WT; $\mathrm{n}=13$ at $1 \mathrm{ng} ; \mathrm{n}=12$ at $10 \mathrm{ng} ; \mathrm{n}=18$ at $100 \mathrm{ng}, \mathrm{KO} ; \mathrm{n}=20$ at $100 \mathrm{ng} ; \mathrm{n}=26$ at $1000 \mathrm{ng} ; \mathrm{n}=23$ at $10000 \mathrm{ng}$ ). The different letters indicate significant differences according to Fisher's exact probability test. (b) Pheromone source localisation time of BmPBP1-knockout (blue) and wild-type (red) male moths at $2 \mathrm{~Hz}(\mathrm{KO} ; \mathrm{n}=10$ at $100 \mathrm{ng} ; \mathrm{n}=20$ at $1000 \mathrm{ng} ; \mathrm{n}=17$ at $10000 \mathrm{ng}$, WT; $\mathrm{n}=11$ at $1 \mathrm{ng} ; \mathrm{n}=10$ at $10 \mathrm{ng} ; \mathrm{n}=15$ at $100 \mathrm{ng}$ ). Error bars represent \pm SEM. The different letters indicate significant differences according to the Steel-Dwass test. Black solid circles indicate the distribution of individual data. (c) Representative trajectory of BmPBP1-knockout (blue) and wild-type male (red) moths to tested bombykol dosage (WT: 1, 10, $100 \mathrm{ng}, \mathrm{KO}: 100,1000,10000 \mathrm{ng}$ ) during pheromone source localisation. Bombykol pulse stimuli were applied for $200 \mathrm{~ms}$ at $2 \mathrm{~Hz}$. Solid lines indicate the trajectory of the pheromone source localisation behaviour. Broken lines indicate the estimated boundaries of the pheromone plume. (d) Surge distance of BmPBP1-knockout (blue) and wild-type (red) male moth to bombykol pulse trains at $2 \mathrm{~Hz}$ (WT; n=11 at 1 ng; $n=10$ at $10 \mathrm{ng} ; \mathrm{n}=15$ at $100 \mathrm{ng}, \mathrm{KO} ; \mathrm{n}=10$ at $100 \mathrm{ng} ; \mathrm{n}=20$ at $1000 \mathrm{ng} ; \mathrm{n}=17$ at 10000 ng). (e) All turn angles of BmPBP1-knockout (blue) and wild-type (red) male 
660 moths to bombykol pulse trains at $2 \mathrm{~Hz}$ (WT; $n=11$ at $1 \mathrm{ng} ; \mathrm{n}=10$ at $10 \mathrm{ng} ; \mathrm{n}=15$ at 100 $661 \mathrm{ng}, \mathrm{KO} ; \mathrm{n}=10$ at $100 \mathrm{ng} ; \mathrm{n}=20$ at $1000 \mathrm{ng} ; \mathrm{n}=17$ at $10000 \mathrm{ng}$ ). (f-i) Performance of 662 pheromone source localisation to a female moth. Success rate (WT; $n=10, K O ; n=8$ ), 663 localisation time (WT; $\mathrm{n}=7, \mathrm{KO} ; \mathrm{n}=5)$, surge distance $(\mathrm{WT} ; \mathrm{n}=7, \mathrm{KO} ; \mathrm{n}=5)$, and all turn 664 angles (WT; $\mathrm{n}=7, \mathrm{KO} ; \mathrm{n}=5$ ) to a female moth. The asterisks indicate significant 665 differences between the groups $(* * p<0.01)$, as determined using Student's $t$-test for 666 comparing pairs of data. NS indicates not significant. 
Figure 1

(a)

(b)

Bombykol

Bombykal

bioRxiv preprint doi: https://doi.org/10.1101/2021.01.11.426239; this version posted January 12, 2021. The copyright holder for this preprint (which was not certified by peer review) is the author/funder. All rights reserved. No reuse allowed without permission.
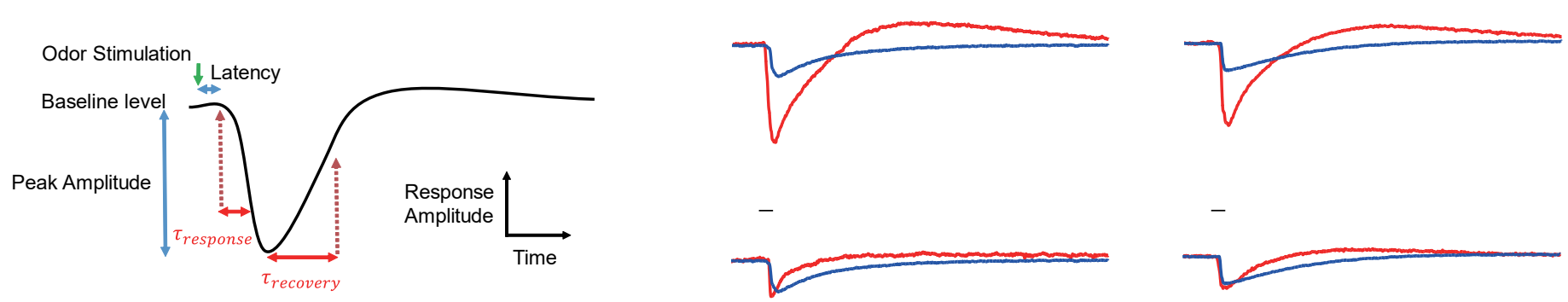

$0.5 \mathrm{mV}$

$1 \mathrm{sec}$

(c)
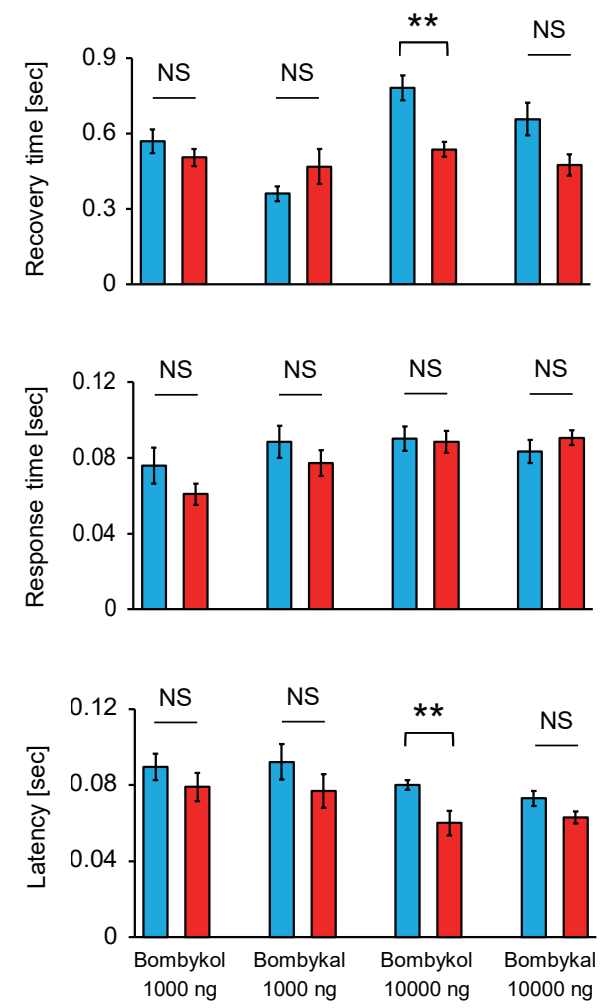

(d)

Bombykol

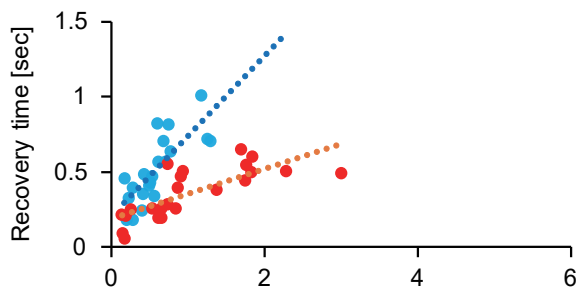

NS

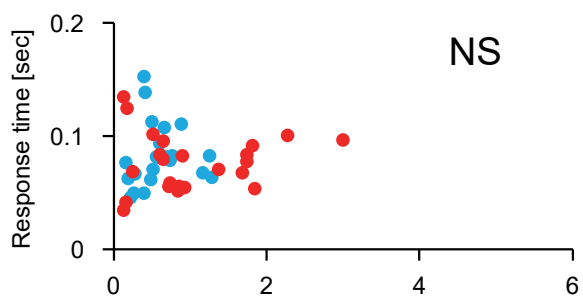

NS

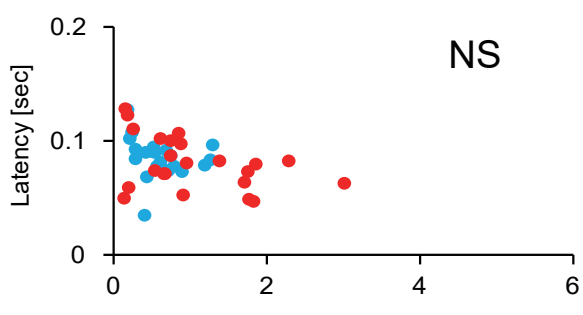

Bombykal
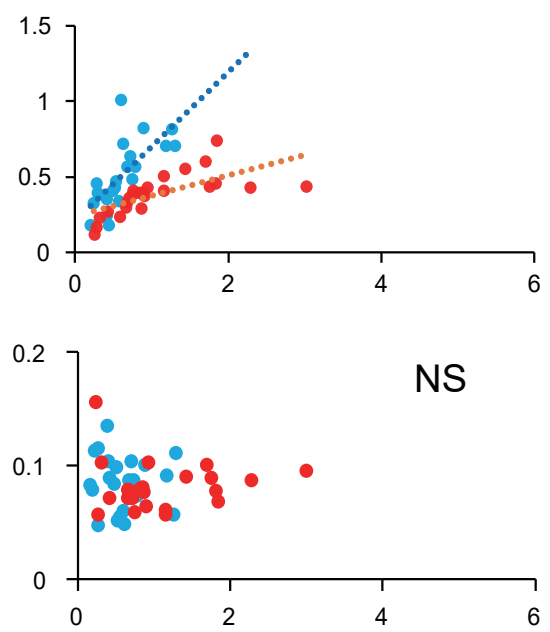

NS

EAG response amplitude [mV]

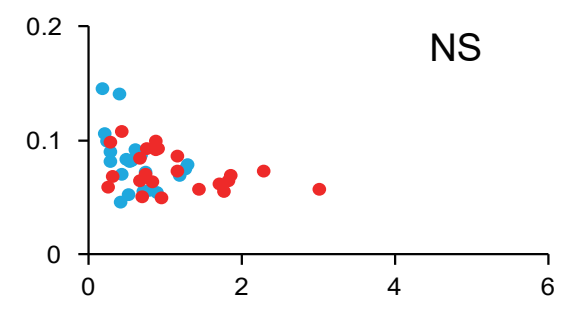




\section{Figure 2}

(a)

bioRxiv preprint doi: https://doi.org/10.1101/2021.01.11.426239; thisาversion-posted January 12, 2021. The copyright holder for this preprint

- (which was not certified by peer review) is the author/funder. All rights reserved. No reuse allowed without permission.

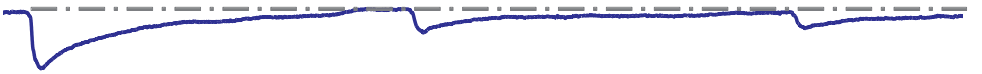

$0.17 \mathrm{~Hz}$
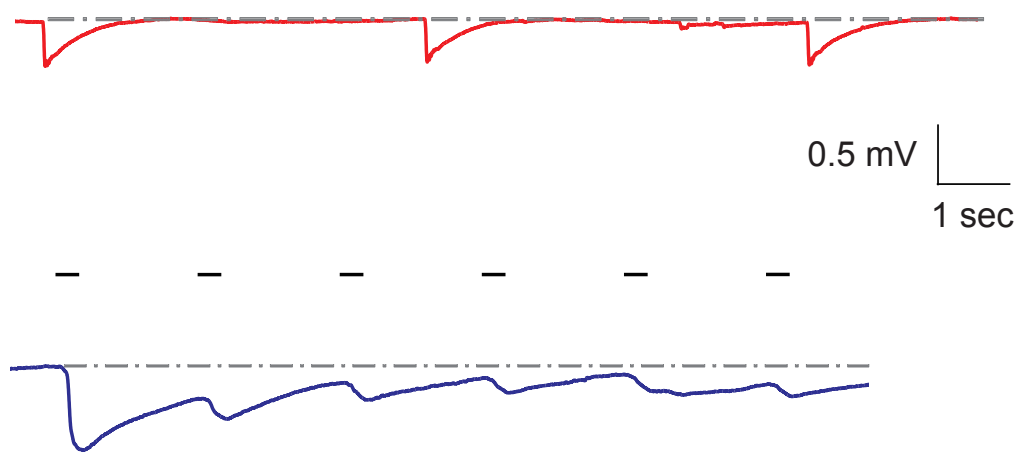

$0.83 \mathrm{~Hz}$
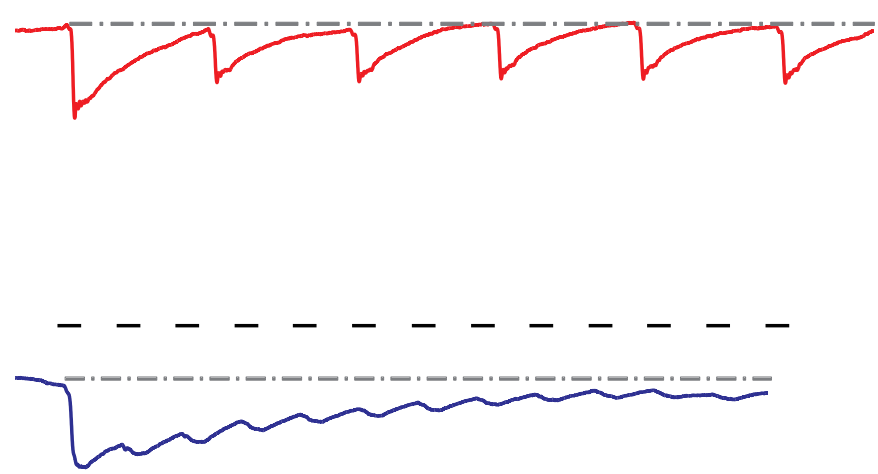

$2 \mathrm{~Hz}$

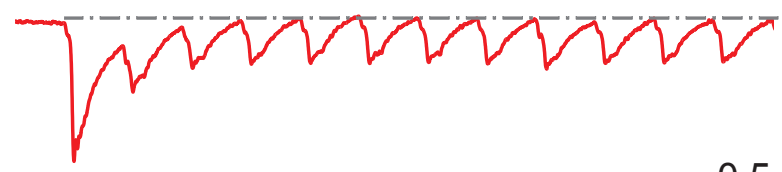

(b)

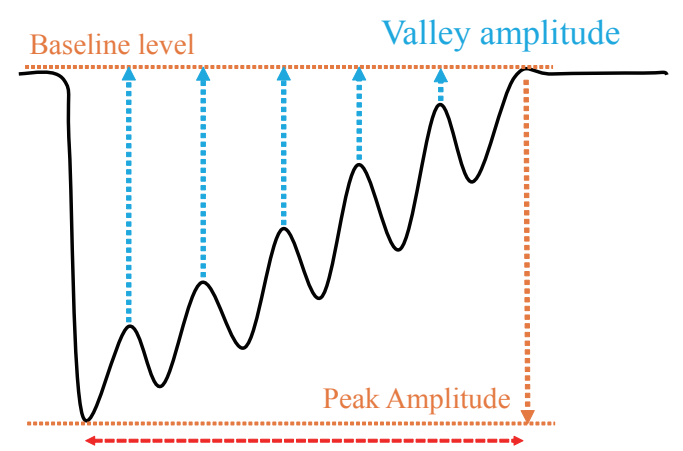

Termination time Amplitude wild-type

$$
0.5 \mathrm{mV} \frac{\mid}{1 \mathrm{sec}}
$$

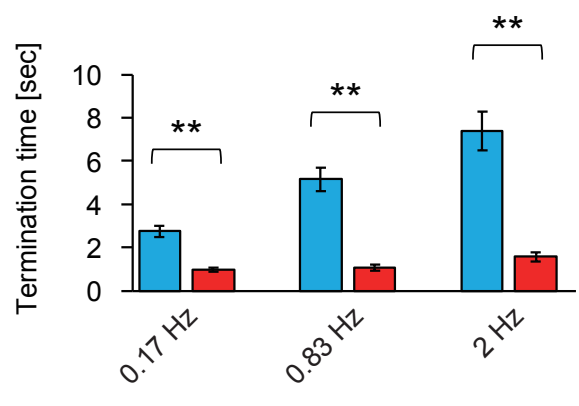

(d)
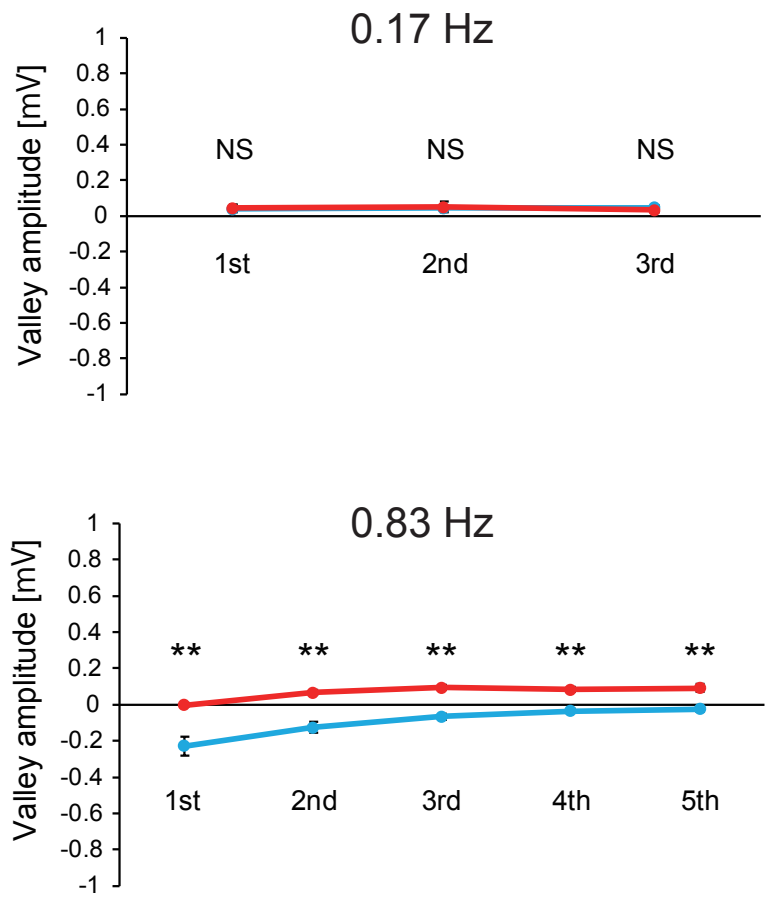

Response

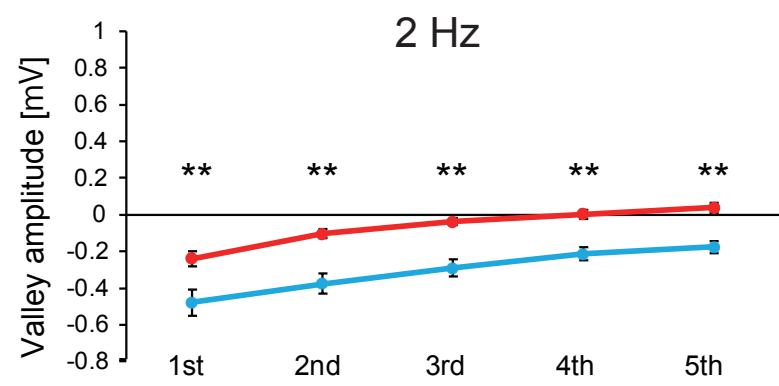




\section{Figure 3}

(a)

$0.17 \mathrm{~Hz}$

BMPBP1-KO

(b)

$0.17 \mathrm{~Hz}$

(d)

bioRxiv preprint doi: https://doi.org/10.1101/2021.01.11.426239; this version posted January 12, 2021. The copyright holder for this prepristx (which was not certified by peer review) is the author/funder. All rights reserved. No reuse allowed without permission.
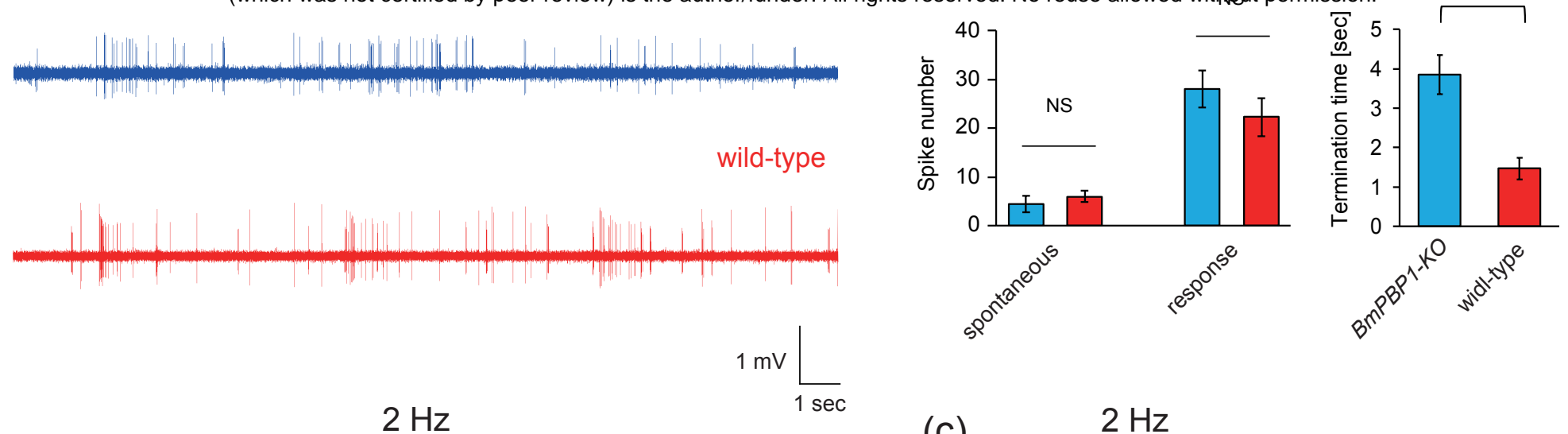

(c) $2 \mathrm{~Hz}$
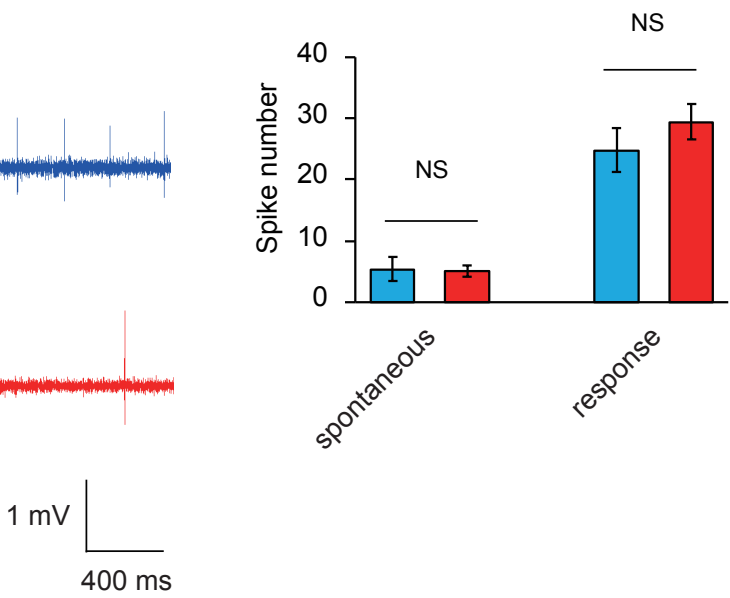

(e)

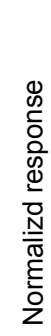

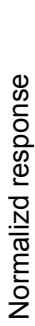

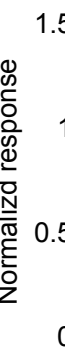

$0.17 \mathrm{~Hz}$
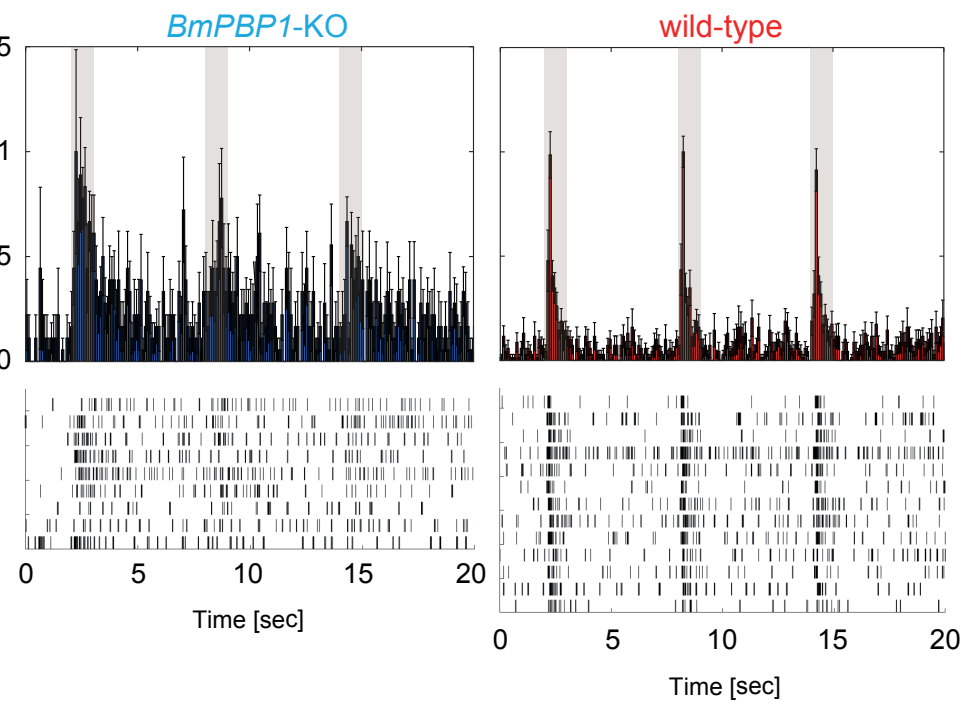

BMPBP1-KO

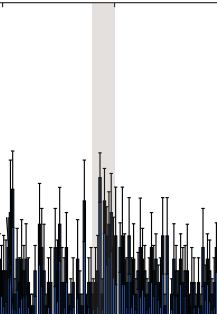

$2 \mathrm{~Hz}$

(f)
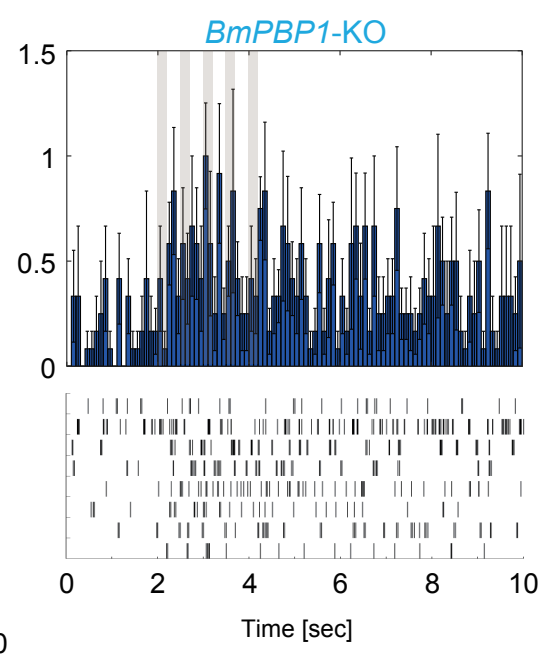
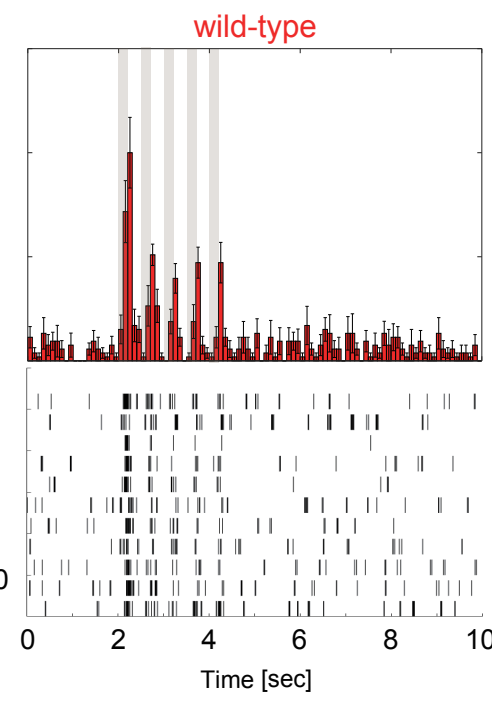


\section{Figure 4}

(a)

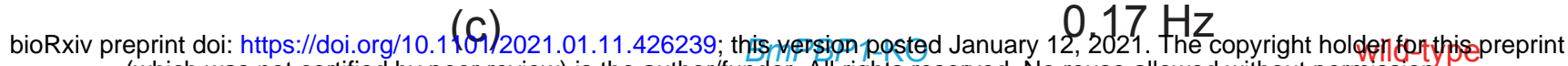
(which was noф certified by peer reviews) is the author/funder. All rights reserved. No reuse allowed without permission.
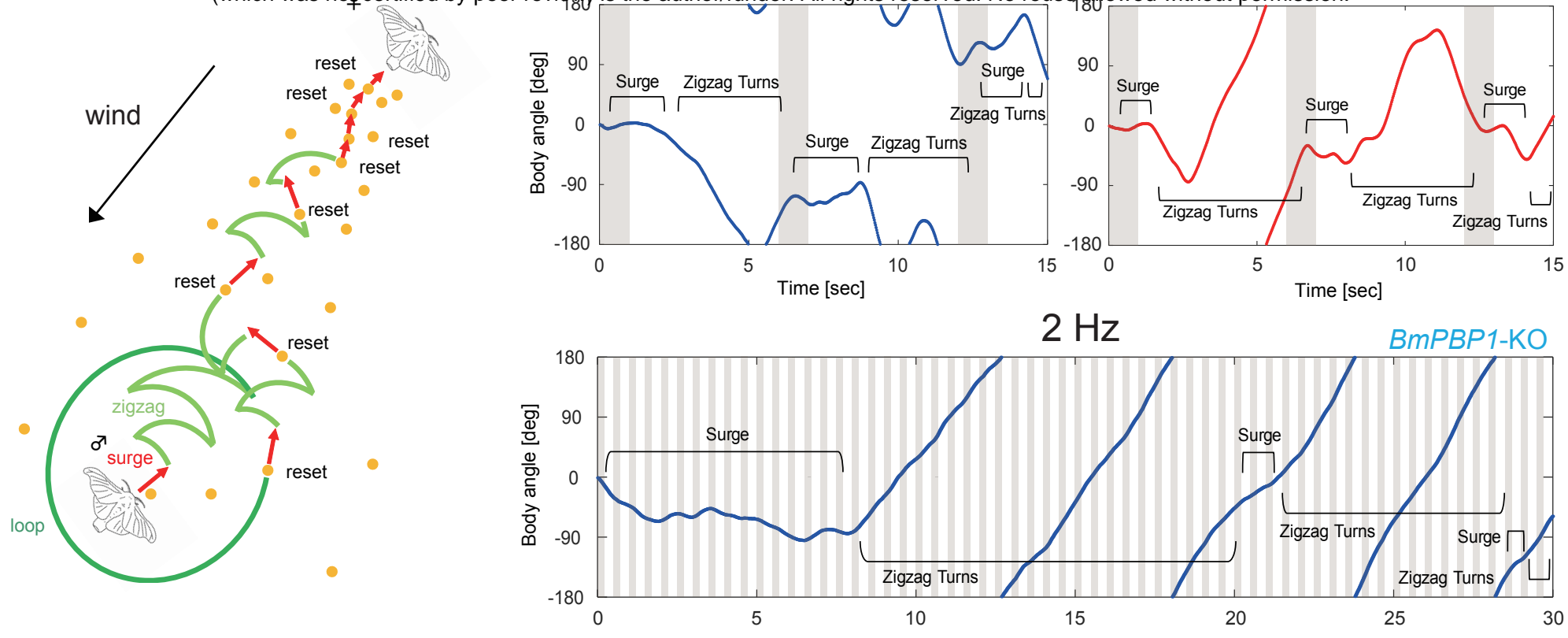

(b)
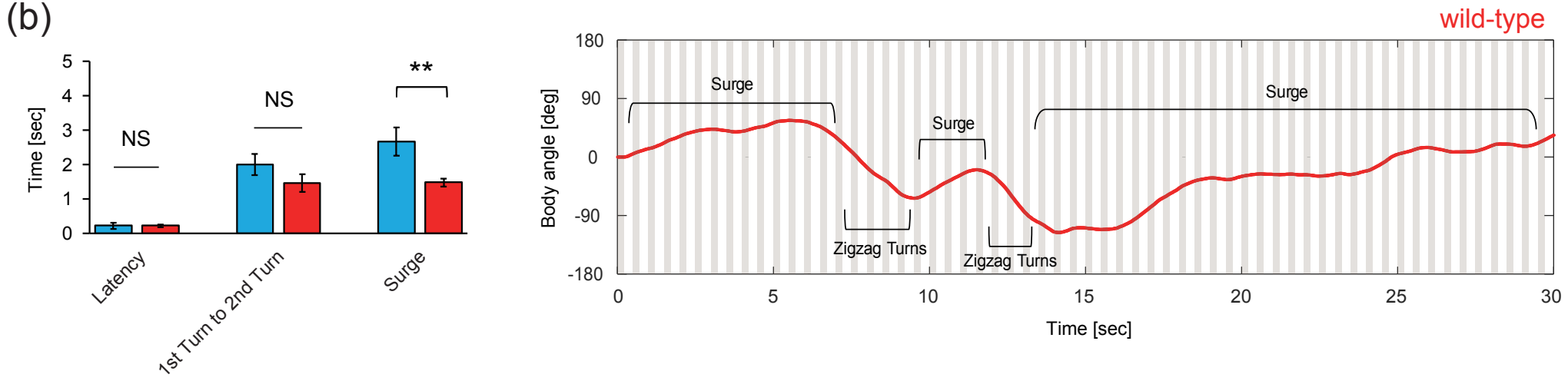

(d)

(e)
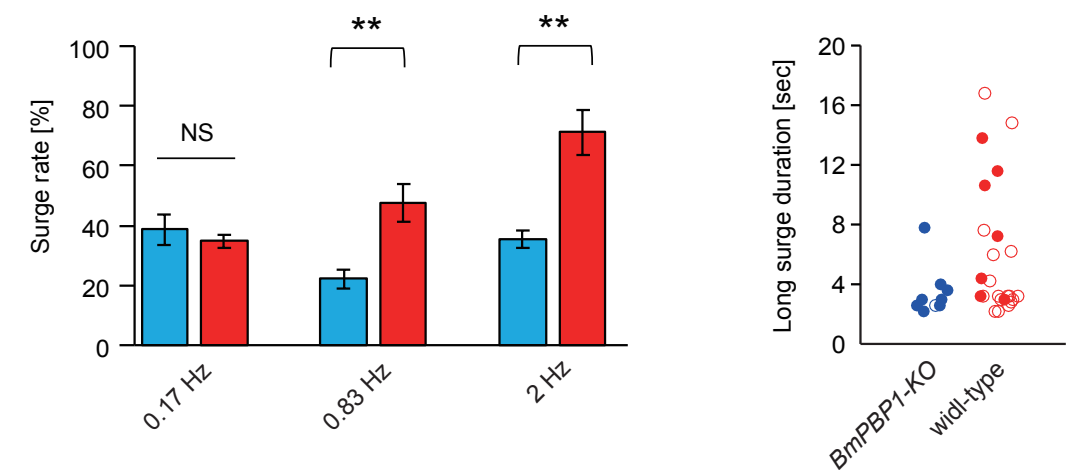


\section{Figure 5}

(a)

(b)

bioRxiv preprint doi: https://doi.org/10.1101/2021.01.11.426239; this version posted January 12, 2021. The copyright holder for this preprint

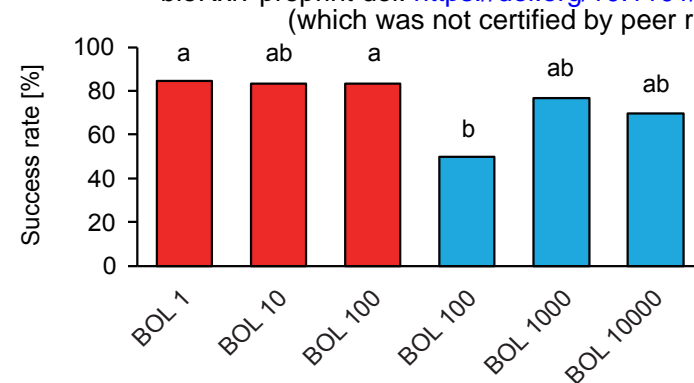

(c)

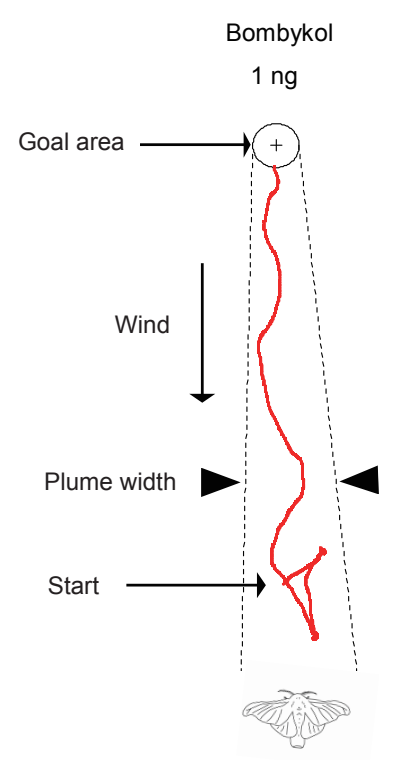

(d)

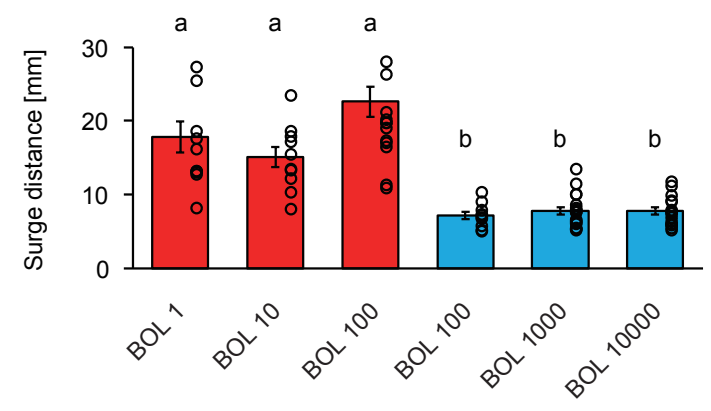

(e)

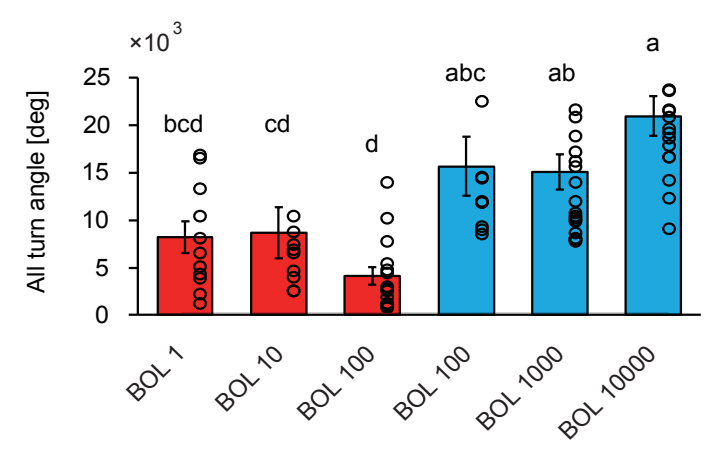

wild-type

$$
\begin{gathered}
\text { Bombykol } \\
10 \mathrm{ng}
\end{gathered}
$$

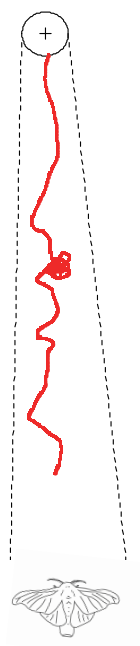

(f)

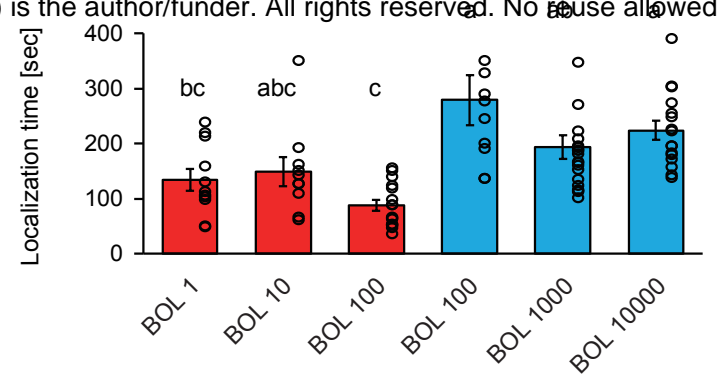

\section{BMPBP1-KO}

$$
\text { Bombykol }
$$

$100 \mathrm{ng}$

Bombykol
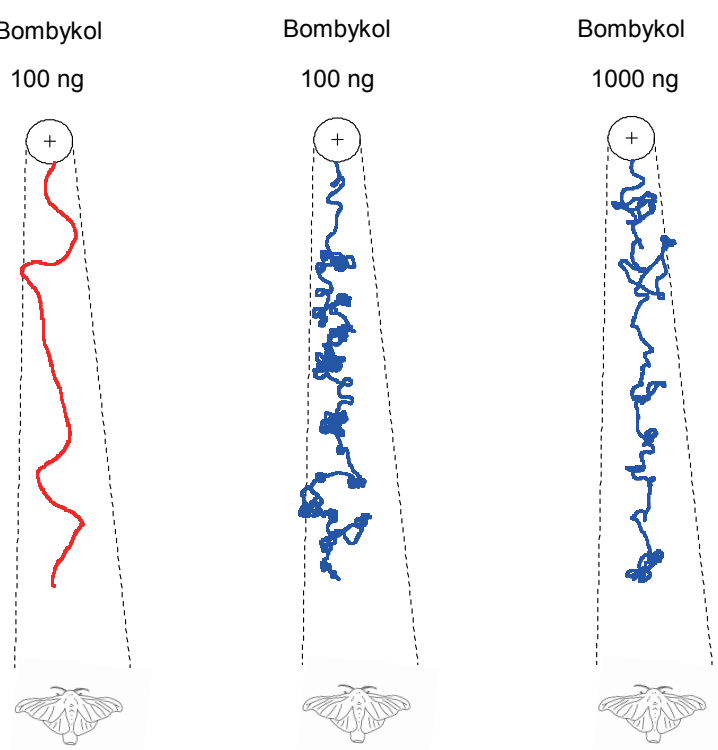

(h)

Bombykol

$10000 \mathrm{ng}$

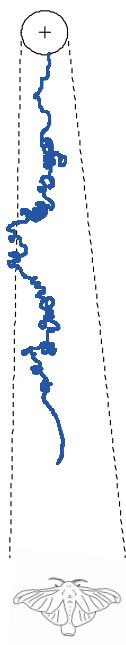

$100 \mathrm{~mm}$

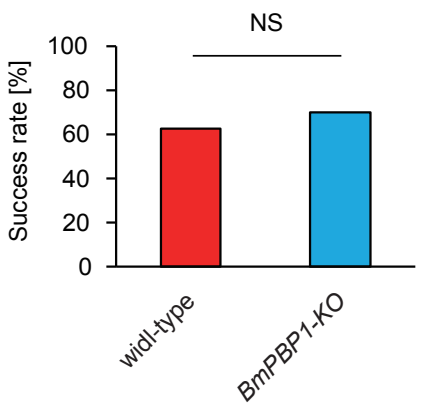

(g)

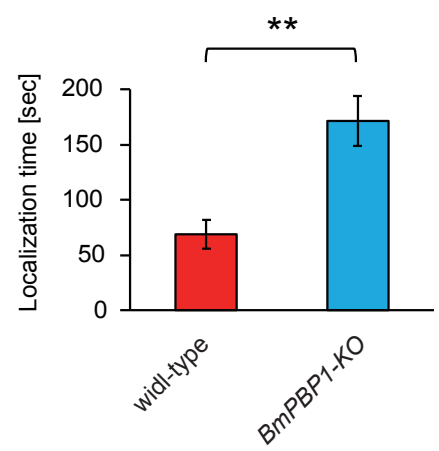

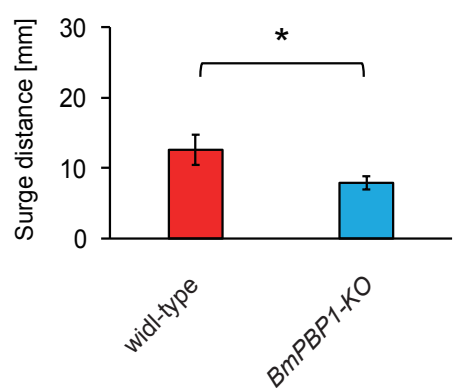

(i)

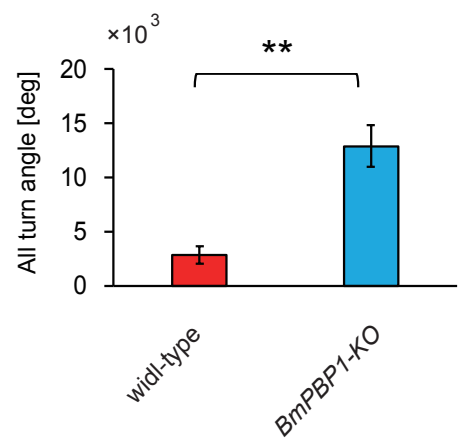

